\title{
An Acoustic Study of Communication Apprehension during English Oral Presentations by Japanese University Students
}

\author{
Hiroko Nakamura $^{1}$, Kazuhiro Nomura ${ }^{2} \&$ Namie Saeki ${ }^{3}$ \\ ${ }^{1}$ Genreral Education Center, Tottori University of Environmental Studies, Tottori, Japan \\ ${ }^{2}$ Department of English Studies, Kobe City University of Foreign Studies, Hyogo, Japan \\ ${ }^{3}$ Department of Internatinal Studies, Faculty of Leberal Arts, Doshisha Women's College, Kyoto, Japan \\ Correspondence: Hiroko Nakamura, General Education Center, Tottori University of Environmental Studies, \\ 1-1-1 Wakabadai-kita, Tottori, 689-1111, Japan.
}

Received: July 1, 2020

Accepted: July 29, 2020

Online Published: July 30, 2020

doi: 10.5539/elt.v13n8p178

URL: https://doi.org/10.5539/elt.v13n8p178

\begin{abstract}
This study investigated the influence of communication apprehension and anxiety in second-language (L2) learning on oral performance of Japanese university students in terms of F0 (fundamental frequency) analysis. The participants were English-major students ( 3 males and 6 females) who presented at an oral communication festival for university students. The F0 analysis consisted of a mean F0 and F0 range. The participants' utterances were digitized and analysed with Praat. Participants also completed two structured closed-ended questionnaires: a Personal Report of Communication Apprehension (PRCA) and a Foreign Language Classroom Anxiety Scale (FLCAS). One subscale of PRCA is Speech Anxiety (SA) that measures apprehension in public speaking. Acoustic analysis of F0 was conducted of the utterances provided by the students and their F0 data during rehearsal and the actual performance settings. The results revealed a significant difference in mean F0 between the rehearsal and actual performance. Mean F0 was significantly correlated with SA. These results suggest that students tend to show higher speech anxiety during an actual performance setting that is also reflected by a higher speaking F0.
\end{abstract}

Keywords: F0 analysis, communication apprehension, L2 anxiety, oral performance

\section{Introduction}

Japanese university students have higher communication apprehension than other Asian peers (Klopf \& Cambra, 1979) and students with higher communication apprehension were reported to have higher L2 learning anxiety (Nakamura et al., 2013). English education in Japan places considerable emphasis on improving speaking fluency of students and are planning to include a speaking test as part of the entrance examination to university. In spite of the government-led English language teaching that started in the 1990s, the mean TOEFL speaking scores of Japanese students have lagged behind many other Asian countries for years (Educational Testing Service, 2017). As a consequence of needing to improve English communication skills in English, students who have communication apprehension often feel discouraged to participate in speaking activities. With increased attention to affective factors including communication apprehension and anxiety, researchers in Japan have examined the influence of anxiety on L2 learning (Asano, 2003; Fujii \& Fujisawa, 2014; Koizumi, 2004; Norman, 2012; Osuboe et al., 2007; Yashima, 2004). Horwitz, Howitz and Cope (1986) reported that among the four L2 skills (reading, writing, speaking \& listening), speaking yields the highest foreign language anxiety. Accordingly, fear of speaking English could be a major obstacle to improving overall English proficiency.

The present study aims to examine the effects of communication apprehension and L2 learning anxiety on oral presentation as reflected acoustically in the speaker's vocal fundamental frequency (F0). Previous acoustic studies on anxiety of speaking (Jones et al., 2011; Laukka et al., 2008) of non-Asian speakers have indicated that elevated anxiety is reflected by a corresponding increase in mean F0. The purpose of the current study was to explore whether a similar pattern of vocal F0 was evident in Japanese university students. That is, is there a relationship between an individual's communication apprehension for L2 learning and his/her corresponding F0? Acoustic measurements were taken from the recording of oral performance and correlated with the scores of scales on 
communication apprehension (Personal Report of Communication Apprehension) and L2 anxiety (Foreign Language Classroom Anxiety Scale).

\section{Communication Apprehension and L2 Language Anxiety}

Not many Japanese people who have learned English as a second language (L2) become fluent speakers of English. One of the limiting factors for this finding is that they exhibit fear or anxiety of communicating orally with other people. A number of authors have attempted to examine the impact of anxiety in both native language (L1) and L2 learning. The research on L1 anxiety has been conducted under the labels of communication apprehension (CA) or shyness (Crozier \& Hosteeler, 2003; Daly \& McCroskey, 1984; McCroskey, 1977). McCroskey (1977) pointed out that the apprehensive person not only feels nervous in public speaking situations, but also experiences nervousness when talking to a peer or participating in a group.

A number of studies on L2 language anxiety have accumulated since the 1980s and the negative effect of anxiety on L2 learning has been widely reported (Aida, 1994; Al-Shboul et al., 2013; Clement et al., 1994; Gardner \& MacIntyre, 1993; Horwitz et al., 1986; MacIntyre \& Gardner, 1991, 1994; Osboe et al., 2007). Language anxiety, a situation-specific apprehension generated in L2 learning, has been shown to correlate more negatively with L2 achievement than attitude and motivation (Al-Shboul et al., 2013; Gardner \& MacIntyre, 1993). It has been also reported that L2 speaking is more anxiety-provoking than L1 speaking (Horwitz et al., 1986; MacIntyre \& Gardner, 1991).

Most of the studies on anxiety both in L1 and L2 are based mainly on survey results with scales to measure variables concerning affective characteristics. One of the scales commonly used to assess communication apprehension is the Personal Report of Communication Apprehension (PRCA) developed by McCroskey (1970). The instument uses a 5-point Likert scale and includes 24 questions that are categorized into four different situations: group discussions, meetings, dyads, and public speaking. According to Kondo and Yong (1995), among the four situations, public speaking could cause the highest apprehension both in L1 and L2. The subscale for communication apprehension in public speaking is speech anxiety (SA).

The Foreign Language Classroom Anxiety Scale (FLCAS) developed by Howitz et al. (1986) has been mainly used to measure the amount of anxiety that students may experience in learning L2. This scale has 33 items scored on a 5-point Likert scale. Based on the results provided by FLCAS, researchers identified a significant inverse relationship between L2 anxiety and oral proficiency (Phillips, 1992). Phillips (1992) investigated the effect of language anxiety on L2 proficiency in university students and found a significant inverse relationship between their language anxiety and ability to perform on oral exams.

In the early stage of research on L2 language anxiety, most of the studies that were conducted focused on Western languages (Ali, 2016). Aida (1994) in particular emphasized the importance of including non-Western languages to explore the negative effect of anxiety on L2 learning. As Al-Shboul et al. (2013) reviewed in their study, there have been more research available regarding inverse negative effect of L2 learning anxiety on oral proficiency among Asian students (Lu \& Liu, 2011; Park \& Lee, 2005). More recently, Ali (2017) included the scale on delivering a presentation in English to measure speaking anxiety among university students in Egypt.

Regarding Japanese university students, Norman (2012) conducted a survey to compare shyness in L1 and L2 and indicated that $85 \%$ of respondents regarded themselves as being shy as a personal trait. In addition, $93 \%$ of those students answered "they are shy" when they speak English in the classroom. This study suggested that L1 anxiety could affect L2 speaking skills. Nakamura et al. (2013) carried out a cross-cultural study on communication apprehension and L2 anxiety among Japanese, Taiwanese, and Korean university students. The instrument used in this study was the Erikson S-24 Scale of Communication Attitudes (Andrew \& Cutler, 1976), which was originally developed to measure apprehension in individuals who stutter. The results demonstrated that Japanese students had significantly higher communication apprehension than Korean and Taiwanese students. This result is consistent with the previous study reported by Klop and Cambra (1979). Nakamura et al. (2013) also reported that communication apprehension and L2 anxiety were significantly correlated.

According to previous studies, the high communication apprehension of Japanese students seems to impede the development of their English speaking skills. To explore whether the anxiety both in L1 and L2 was evident in their speech production, acoustic measurements of F0 were performed. Most studies on communication apprehension and L2 language anxiety are based primarily on the results of questionnaires, and the number of acoustic studies is limited. Laukka et al. (2008) investigated acoustic correlates of anxiety with the speech of Swedish people with social phobia and found that the values of mean F0 and maximum F0 were higher in an anxiety provoking situation. A similar finding was obtained by Jones et al. (2011) for Greek participants and 
reported an increase in mean F0 and reduction in the F0 range. However, a study by Tolkmitt and Scherer (1986) for German speakers found no increase in mean F0, but an increase in minimum F0.

The purpose of the present study was to compare the F0 characteristics of speech produced by Japanese university students between their rehearsal and the actual speaking performance and examine the influence of affective factors on F0 values.

The following research questions were posed:

RQ1: Are mean F0 and F0 range in the utterances of Japanese university students different between the rehearsal and the actual performance?

RQ2: Is there any relationship between F0 and corresponding scores of PRCA, FLCAS, and SA?

\section{Methods}

\subsection{Participants and Procedures}

Nine English major students ( 3 males \& 6 females) aged 20 to 22 participated in an oral communication festival including the rehearsal held on the same day. Four (M1, F1, F2, F3) students presented a recitation (Performance 1). Five (M2, M3, F4, F5, F6) students performed a drama (Performance 2). Each partitipant's performance was video recorded on two separate occasions. The first occasion was during rehearsals which were held in the morning. The second occasion was during the actual performances held in the afternoon. Three consecutive phrases of speech were audio recorded from each participant during the rehearsal and actual performance. The content of the phrases differed for each participant. An average number of five words comprised each phrase. The same samples of speech were analysed for the rehearsal and the actual performance. A pair of vertical cursors were placed at the onset and offset point of the samples using Praat (version: 6.1.08), computer software for speech analysis in phonetics. The software automatically calculated the overall mean F0, minimum F0, and maximum F0 for the sample. Each F0 range was calculated in Excel. Three days following the performances, each participant was asked to complete the questionnaires on communication apprehension (PRCA: Personal Report of Communication Apprehension) and L2 learning anxiety (FLCAS: Foreign Language Classroom Anxiety Scale). Both of the scales were the Japanese versions and 24 items out of the original 33 items were used for FLCAS to match the number of PRCA. Speech Anxiety (SA), one of the subscales of PRCA, was also calculated. The speech samples in this study were obtained from the oral performance in public. The possible range of score is $24-120$ for PRCA and FLACAS and 6-30 for SA.

\subsection{Measurement Reliability}

In order to evaluate the intra-judge reliability for measurement of F0, a total of $20 \%$ of the original audio recordings were selected for reanalysis by the first author. The average difference between the initial measurments and the re-measured samples was $3.5 \mathrm{~Hz}(\mathrm{SD}=5.43)$. The Speaman's rank correlation computed for the first and second measurements of F0 indicated a significant relationship $(r=0.98 ; p<.001)$. Inter-judge measurement reliability was also determined by using the same $(20 \%)$ sample of the original recordings. An individual who possessed extensive experience with acoustic analysis techniques was recruited to undertake an analysis of the samples. The results of this analysis were then compared to the initial analyses of the first author. The resultant measurement difference was $6.7 \mathrm{~Hz}(\mathrm{SD}=7.71)$. The Speaman's rank correlation coefficient for inter-judge measurement of F0 was significant $(r=0.97 ; \mathrm{p}<.001)$.

\section{Results}

The total number of phrases anlayzed for mean F0, minimum F0, maximum F0 and F0 range was 27 (3 phrases $\times 9$ students). The results are reported in three sections. The first section provides an analysis of differences in mean F0, minimum F0, maximum F0 and F0 range between the rehearsal and the actual performance. The second section shows the correlation between affective factors and F0 values. The third section indicated the scores for FLCAS, PRCA, and SA of each participant and its corresponding mean F0 values at the rehearsal and the actual performance.

\section{Mean Fo}

The mean F0 value for the rehearsal and the actual performance was $264 \mathrm{~Hz}(\mathrm{SD}=83 \mathrm{~Hz})$ and $311 \mathrm{~Hz}(\mathrm{SD}=95$ $\mathrm{Hz}$ ), respectively. The Wilcoxon rank sum test was used to examine the difference and the results showed that the mean F0 values were significantly higher at the actual performance than the rehearsal $(z=2.21, p=0.02)$.

\section{Minimum F0}

The minimum F0 value for the rehearsal and the actual performance was $150 \mathrm{~Hz}(\mathrm{SD}=74 \mathrm{~Hz})$ and $177 \mathrm{~Hz}(\mathrm{SD}=$ $89 \mathrm{~Hz}$ ), respectively. Results of a Wilcoxon rank sum test was used to examine the difference in F0 between the rehearsal and the actual performance. The test was significant indicating a higher minimum F0 during the actual performance compared to the rehearsal $(\mathrm{z}=1.96, \mathrm{p}=0.049)$. 


\section{Maximum F0}

The maximum F0 value for the rehearsal and the actual performance was $395 \mathrm{~Hz}(\mathrm{SD}=129 \mathrm{~Hz})$ and $426 \mathrm{~Hz}(\mathrm{SD}=$ $102 \mathrm{~Hz})$, respectively. Results of a Wilcoxon test approached significance $(\mathrm{z}=1.85, \mathrm{p}=0.0643)$.

\section{F0 Range}

The F0 range value for the rehearsal and the actual performance was $253 \mathrm{~Hz}(\mathrm{SD}=111 \mathrm{~Hz})$ and $242 \mathrm{~Hz}(\mathrm{SD}=143$ $\mathrm{Hz})$, respectively. Results of a Wilcoxon rank sum test showed no significant difference $(z=0.29, \mathrm{p}=0.7731)$.

The group F0 data for the rehearsal and the actual performances are provided in Figure 1.

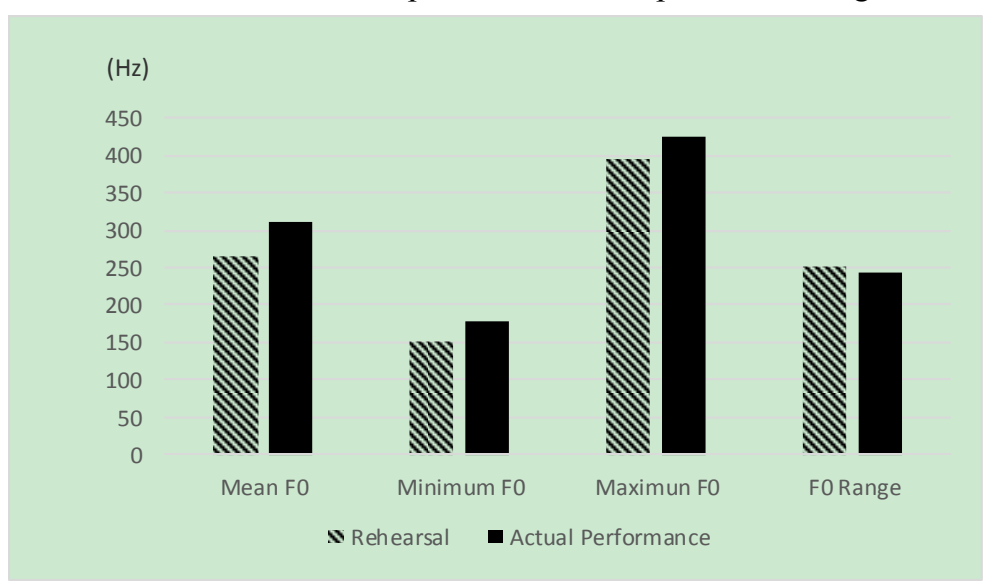

Figure 1. Mean fundamental frequency (F0), Minimum F0, Maximum F0, and F0 range for the group of participants during rehearsal and actual oral performance

\section{Affective Factors and F0 Values}

A series of Speaman's rank correlations were performed between F0 values and each score for PRCA, SA, and FLCAS. Table 1 shows the results of the various correlations. A significant positive correlation was found between mean F0 and SA $(r=.40 ; \mathrm{p}=.367)$ and a marginally significant correlation was obtained between F0 range and $\mathrm{SA}(\mathrm{r}=.32 ; \mathrm{p}=.1033)$

Table 1. Speaman's Rank Correlations for F0 values and PRCA, SA, and FLCAS scores

\begin{tabular}{lcccc}
\hline Scale & Mean F0 & Minimum F0 & Maximun F0 & F0 Range \\
\hline PRCA & .23 & .01 & -.01 & .03 \\
SA & $.40^{*}$ & .06 & -.11 & .32 \\
FLCAS & -.14 & -.03 & -.11 & .18 \\
\hline
\end{tabular}

Note. ${ }^{*} p<.05$

As shown in Table 1, mean F0 is significantly correlated with the SA scores. In order to examine the relationship between affective factors and mean F0 values more closely, the scores for FLCAS, PRCA, and SA of each participant and its corresponding mean F0 values are indicated repectively for Performance 1 and Peformance 2 in Figue 2 and Figure 3.

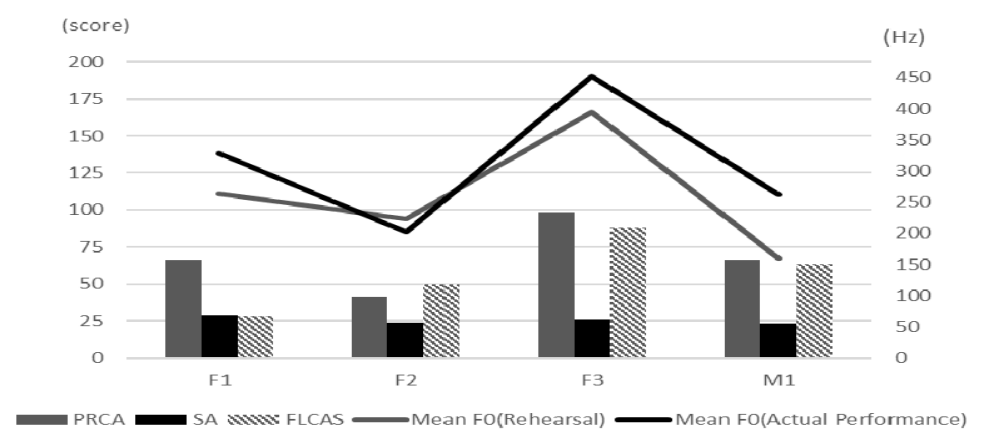

Figure 2. Scores for PRCA, SA \& FLCAS and Mean fundamental frequency (F0) for each participant during rehearsal and actual performance (Performance 1) 


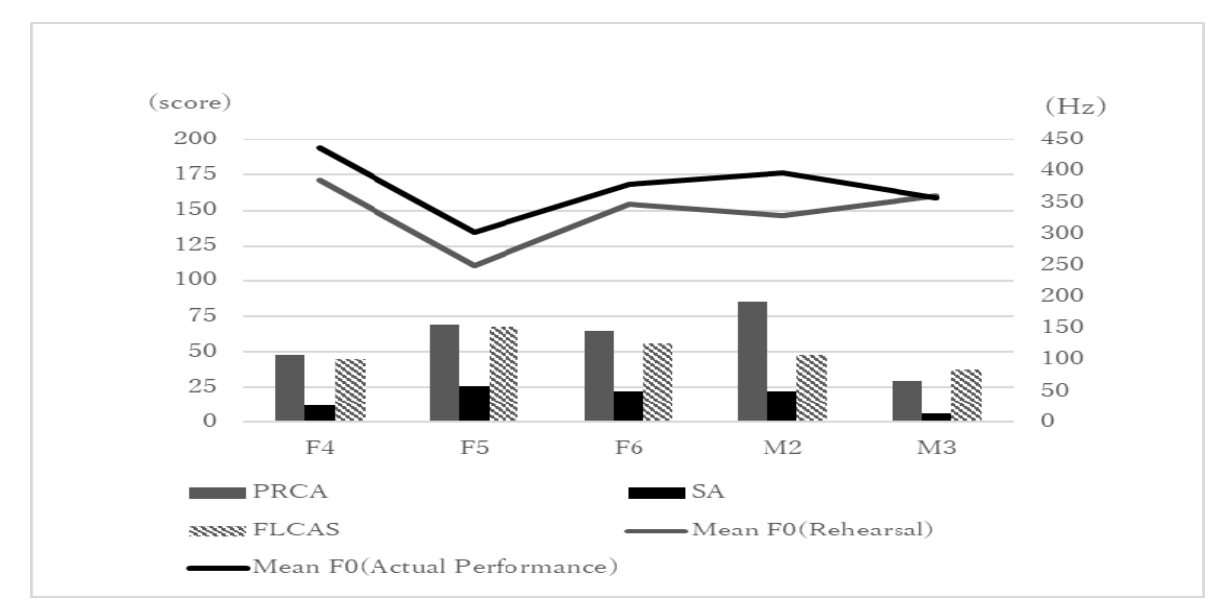

Figure 3. Scores for PRCA, SA \& FLCAS and Mean fundamental frequency (F0) for each participant during rehearsal and actual performance (Performance 2)

\section{Discussion}

The results of this study offer a further demonstration that affective factors could influence oral performance as revealed by an increase in vocal F0. Previous studies exhibited that anxiety increased mean F0 and maximum F0 (Laukka et al., 2008), and showed an increase in mean F0 and a decrease in F0 range (Jones et al., 2011). On the other hand, one study reported no increase in mean F0, but an increase in minimum F0 (Tolkmitt \& Scherer, 1986).

The first research question addressed the change of mean F0 and F0 range between the rehearsal and the actual performance. The present study supports the earlier results of Laukka et al. (2008) and Jones et al. (2011) who found an increase in mean F0. The current study also found minimum F0 value to be significantly higher in the actual performance compared to the rehearsal. This result is consonant with Tolkmitt and Scherer (1986). On the other hand, F0 range values were almost the same, or slightly lower in the actual performance, which is consistent with the result of Jones et al. (2011). The possible question that could arise from this finding is whether participants raised their F0 because they became nervous or they wanted to outwardly express more emotion during the actual performance. Students might speak with more prosodic inflection in their voice during an actual performance, which could serve to raise their mean F0. However, if we consider the results that not only mean F0 values, but also both minimum and maximum F0 values tend to be higher with almost no change of $\mathrm{F} 0$ range, it would be possible to regard higher $\mathrm{F} 0$ as the consequence of nervousness caused by anxiety during the actual performance.

The second research question explored the relationship between F0 values and the scores of FLCAS, PRCA, and SA, respectively. As shown Figure 2 and Figure 3, mean F0 values were higher at the actual performance than the rehearsal for seven participants; only two participants whose PRCA scores were relatively low showed almost the same F0 values at the both settings (M3) and even lower F0 value at the actual performance (F2). In this study, a significant correlation was solely found between mean F0 and F0 range with SA, which indicates anxiety associated with speaking in public. This shows that students who have higher SA tend to speak with a wider F0 range. This result is not consistent with Jones et al. (2011). These results possibly suggest that higher minimum F0 values for students with higher speech anxiety in the actual performance lead to higher mean F0 value, but the change in maximum F0 in the actual performance could be different among participants with different levels of speech anxiety. This could explain why there was no difference in F0 range value between the rehearsal and the actual speaking performance. Considering the negative correlations between maximum F0 and SA, it seems that higher anxiety inhibits more intonation with emotion.

It has been long recognized that Japanese speak English with flat intonation (Yamane, 2019). Yabuuchi and Satoi (2001) reported that students who spoke with a wider F0 range showed higher intelligibility and more naturalness in English according to the judgement of native speakers. In order to improve the skills associated with prosodic features of English, making more use of drama-syle performances in an English classroom should be encournaged. The enjoyment of performing a drama is expected to reduce L2 speking anxiety.

In summary, the present study provided evidence that speaking anxiety could affect L2 oral performance as reflected by an increase in vocal F0. This increase in mean F0 is likely to be reflective of nervousness that students feel when they are required to vocally perform. This study possibly indicated that acoustic measures could be used to explore the effect of affective factors on L2 learning. Since oral performance is now a common speaking 
component of English learning for Japanese students, more considerations for affective factors might be needed in communication-based English classes.

Finally, a word of causion is warranted regrading the influence of anxiety on vocal F0. We recognize that the number of participants and speech samples obtained were small and thus the F0 results in this study should be considered preliminary. For further research, a longitudinal acoustic study on speaking anxiety in the English classroom could be conducted to evaluate the improvement of prosodic features of English as well as the effect of affective factors on L2 learning among Japanese students.

\section{Acknowledgements}

The authors are deeply indebted to Dr. Michale Robb for his valuable suggestions. We are also grateful to Professor Tomoko Yamamoto, Professor Sean Banville, and Professor Anna Hirata for their assistance. We would like to thank the anonymous reviewers who offered insightful comments and suggestions. This study was supported by the special grant for a joint-study provided by Tottori University of Environmental Studies.

\section{References}

Aida, Y. (1994). Examination of Horwitz, Horwitz and Cope's construct of foreign language anxiety: The case of students of Japanese. Modern Language Journal, 78, 155-168. https://doi.org/10.1111/j.1540-4781.1994.tb02026.x

Al-Shboul, M. M., Ahmad, I. S., Nordin, M. S., \& Rahman, Z. (2013). A Foreign Language Anxiety and Achievement: Systematic Review. International Journal of English Linguistics, 3(2), 32-45. https://doi.org/10.5539/ijel.v3n2p32

Andrews, G., \& Cutler, J. (1976). Stuttering therapy: The relation between changes in symptom level and attitudes. Journal of Speech Hearing Disorders, 39, 312-319. https://doi.org/10.1044/jshd.3903.312

Asano, S. (2003). Some effect of Audio-visual approaches on foreign language learning anxiety. Bulletin of Osaka University of Health and Sports Science, 34, 65-82.

Australia, Japan, \& Korea. Journal of Psychology, 102, 27-31.

Clement, R., Dornyei, Z., \& Noels, K. (1994). Motivation, self-confidence, and group-cohesion in the foreign language classroom. Language Learning, 44, 418-448. https://doi.org/10.1111/j.1467-1770.1994.tb01113.x

Crozier, W., \& Hostettler, K. (2003). The influence of shyness on children's test. British Journal of Educational Psychology, 73, 317-328. https://doi.org/10.1348/000709903322275858

Daly, J., \& McCroskey, J. (Eds.). (1984). Avoiding communication, shyness, reticence, and communication apprehension. Beverly Hills, CA: Sage.

Educational Testing Service (2017). TOEFL iBT Tests Test and Score Data Retrieved from https://www.ets.org/ s/toefl/pdf/94227_unlweb.pdf

Fujii, S., \& Fujisawa, S. (2014). Relationship between Leaning Anxiety and Motivation in Second Language Learning. Bulletin of Chugokuchiku CASELE, 44, 61-70.

Gardner, R., \& Macintyre, P. (1993). On the measurements of affective variables in second language learning. Language learning, 43, 157-194. https://doi.org/10.1111/j.1467-1770.1992.tb00714.x

Hewitt, E.K., \& Stephenson, J. (2012). Foreign language anxiety and oral exam performance: A Replication of Phillips's MLJ study. The modern Language Journal, 96 (2), 170-187. https://doi.org/10.1111/j.1540-4781.2011.01174.x

Horwitz, E. K., Horwitz, M. B., \& Cope, J. (1986). Foreign-Language Classroom Anxiety. Modern Language Journal, 70(2), 125-132. https://doi.org/10.1111/j.1540-4781.1986.tb05256.x

Jones, M., Anagnostou, F., \& Verhoeven, J. (2011). The vocal expression of emotion: An acoustic analysis of anxiety. Proceeding for international Congress of Phonetic Science. Hong Kong.

Khalaf, M. A. (2016). Confirmatory factor of English learning anxiety scale (ELLAS) in the Egyptian context. Interenatinal Educational E-Journal, 5(2), 1-11. https://doi.org/10.17220/ijpes.2017.02.005

Khalaf, M. A. (2017). English Language Anxiety: Development and validation of a brief measure. Interenational Journal of Psychology and Educational studies, 4(2), 42-53. https://doi.org/10.17220/ijpes.2017.02.005

Klopf. D. W., \& Cambra, R. E. (1979). Communication apprehension among college students in America. https://doi.org/10.1080/00223980.1979.9915091 
Koizumi, R. (2004). Attitudes, communication apprehension, and test anxiety among junior high school students. Tsukuba English Education Society, 22, 125-145.

Kondo, D. S., \& Yang, Y. L. (1995). Komyunikeshonfuan no keisei to chiryo. [Communicaiton apprehension and implications for treatment]. Nakanishiya.

Laukka, P., Elenus, E., Fredeikson, M., Furmarks, T., \& Neiberg, D. (2008). Vocal expression in spontaneous and experimentally induced affective speech: Acoustic correlation of anxiety, irritation and resignation. Proceedings for 9th Annual Conference of the International Speech Communication Association.

Lu, Z., \& Liu, M. (2011). Foreign language anxiety and strategy use; A study with Chinese undergraduate EFL learners. Journal of Language Teaching and Research, 2(6), 1298-1305. https://doi.org/10.4304/jltr.2.6.1298-1305

MacIntyre, P., \& Gardner, R. (1991). Language anxiety: Its relation to other anxieties and to processing in native and second languages. Language learning, 41, 513-534. https://doi.org/10.1111/j.1467-1770.1991.tb00691.x

McCroskey, J. C. (1970). Measures of communication-bound anxiety. Speech Monographs, 37, 269-277. https://doi.org/10.1080/03637757009375677

McCroskey, J. C. (1977). Oral communication apprehension: A summary of recent theory and research. Human Communication Research, 4, 78-96. https://doi.org/10.1111/j.1468-2958.1977.tb00599.x

Nakamura, H. (2016). The influence of communication apprehension on anxiety in second-language learning. Journal of Japan Society for Speech Science, 17, 24-35.

Nakamura, H., Kuo, F., Wu, K., Lin, S., Lee, D., Ka, H., \& Lin, E. (2013). Communication Apprehension and L2 Learning Anxiety in Japanese, Korean, and Taiwanese University Students. 9th Asian Pacific Conference on Speech, Language and Hearing.

Norman, J. (2012). Overcoming Shyness in the English Classroom. Shokei Educational Institution Bulletin, 4, $1-18$.

Osboe, S, Fujimura, T., \& Hirschel, R. (2007). Student confidence and anxiety in L2 speaking activities. Proceedings of the Independent Learning Association 2007 Japan Conference.

Park, E., \& Lee, A. R. (2005). L2 learner's anxiety, self-confidence and oral performance. Proceedings of the $10^{\text {th }}$ Conference of PAAL.

Phillips, E. M. (1992). The effects of language anxiety on students' oral test performance and attitudes. Modern Language Journal, 76, 12-26. https://doi.org/10.1111/j.1540-4781.1992.tb02573.x

Tolkmitt, F. F., \& Scherer, K .R. (1986). Effect of experimentally induced stress on vocal parameters. Journal of Experimental Psychology: Human Perception and Performance, 12, 302-313. https://doi.org/10.1037/0096-1523.12.3.302

Yabuuchi, S. \& Satoi, H. (2001). Prosodic characteristics of Japanese EFL leaners' oral reading: Comparison between good and poor readers. Language Education \& Technology, 38, 99-112.

Yamane, S. (2019). Komyunikeshon no tame no eigo onseigaku kenkyu. [Studies in English Phonetics for Communication]. Kansai University Press, 223-226.

Yashima, T. (2004). Gaikokugo komyunikeshon no joui to douki. [Motivation and Affect in Foreign Language Commmunication]. Kansai University Press.

\section{Copyrights}

Copyright for this article is retained by the author(s), with first publication rights granted to the journal.

This is an open-access article distributed under the terms and conditions of the Creative Commons Attribution license (http://creativecommons.org/licenses/by/4.0/). 